\title{
Development of an Integrated Countermeasure Device for Use in Long-Duration Space Flight
}

Tim Streeper ${ }^{1}$, Peter R Cavanagh ${ }^{2}$, Andrea M Hanson ${ }^{2}$, Dana Carpenter ${ }^{1}$, Isra Saeed ${ }^{1}$, John Kornak ${ }^{1}$, Lynda Frassetto ${ }^{1}$, Carlos Grodsinsky ${ }^{3}$, Justin Funk ${ }^{3}$, Stuart M. C. Lee, Barry A Spiering ${ }^{4}$, Jacob Bloomberg ${ }^{5}$, Ajitkumar P Mulavara ${ }^{6}$, Jean Sibonga ${ }^{5}$, Thomas Lang $^{1}$

${ }^{1}$ University of California, San Francisco, ${ }^{2}$ University of Washington, Seattle, WA, ${ }^{3}$ ZIN Technologies, Cleveland, OH, ${ }^{4}$ Wyle Integrated Science and Engineering, Houston, TX, ${ }^{5}$ NASA Johnson Space Center, Houston, TX, ${ }^{6}$ Universities Space Research Association, Houston, TX

Prolonged weightlessness is associated with declines in musculoskeletal, cardiovascular, and sensorimotor health. Consequently, in-flight countermeasures are required to preserve astronaut health. We developed and tested a novel exercise countermeasure device (CCD) for use in spaceflight with the aim of preserving musculoskeletal and cardiovascular health along with an incorporated balance-training component. Additionally, the CCD features a compact footprint, and a low power requirement. Methods: After design and development of the CCD, we carried out a training study to test its ability to improve cardiovascular and muscular fitness in healthy volunteers. Fourteen male and female subjects ( $41.4 \pm 9.0$ years, $69.5 \pm 15.4 \mathrm{Kg}$ ) completed 12 weeks ( 3 sessions per week) of concurrent strength and endurance training on the CCD. Subjects were tested at baseline and after 12 weeks for 1-repetition max leg press strength (1RM), peak oxygen consumption ( $\mathrm{VO}_{2 \text { peak }}$ ), and isokinetic joint torque (ISO) at the hip, knee, and ankle. Additionally, we evaluated subjects after 6 weeks of training for changes in $\mathrm{VO}_{2 \text { peak }}$ and 1RM. Results: $\mathrm{VO}_{2 \text { peak }}$ and 1RM improved after 6-weeks, with additional improvements after 12 weeks $\left(1.95 \pm 0.5,2.28 \pm 0.5,2.47 \pm 0.6 \mathrm{LŸmin}^{-1}\right.$ and 131.2 $\pm 63.9,182.8 \pm 75.0,207.0 \pm 75.0 \mathrm{Kg}$ ) for baseline, 6 weeks, and 12 weeks respectively. ISO for hip adduction, adduction, and ankle plantar flexion improved after 12 weeks of training $(70.3 \pm 39.5,76.8 \pm 39.2$ and $55.7 \pm 21.7 \mathrm{~N}$-m vs. $86.1 \pm 37.3,85.1 \pm 34.3$ and $62.1 \pm 26.4 \mathrm{~N}-\mathrm{m}$ respectively). No changes were observed for ISO during hip flexion, knee extension, or knee flexion. Conclusions: The CCD is effective at improving cardiovascular fitness and isotonic leg strength in healthy adults. Further, the improvement in hip adductor and abductor torque provides support that the CCD may provide additional protection for the preservation of bone health at the hip. 